\title{
Enquête PISA : la publication des résultats et ses répercussions en Allemagne, en France et au Québec
}

12-14

Bernadette Plumelle

\section{OpenEdition \\ Journals}

Édition électronique

URL : https://journals.openedition.org/ries/1792

DOI : $10.4000 /$ ries. 1792

ISSN : 2261-4265

Éditeur

France Education international

Édition imprimée

Date de publication : 1 septembre 2002

ISBN : 978-285420-554-1

ISSN : 1254-4590

Référence électronique

Bernadette Plumelle, «Enquête PISA : la publication des résultats et ses répercussions en Allemagne en France et au Québec », Revue internationale d'éducation de Sèvres [En ligne], 30 | septembre 2002, mis en ligne le 23 novembre 2011, consulté le 05 juillet 2021. URL : http://journals.openedition.org/ ries/1792 ; DOI : https://doi.org/10.4000/ries.1792

Ce document a été généré automatiquement le 5 juillet 2021.

(c) Tous droits réservés 


\section{Enquête PISA : la publication des résultats et ses répercussions en Allemagne, en France et au Québec}

$12-14$

\section{Bernadette Plumelle}

1 En décembre 2001, l'Organisation de Coopération et de Développement Économiques (OCDE) a rendu publics les résultats ${ }^{1}$ du Programme international pour le suivi des acquis des élèves (PISA). Cette étude, réalisée en 2000 dans 32 pays auprès de 250000 jeunes, a été conçue pour fournir des indicateurs internationaux pertinents sur les politiques éducatives, les connaissances et les savoir-faire des élèves âgés de 15 ans, en fin de scolarité obligatoire. L'objectif de l'OCDE étant d'observer « les qualifications [des jeunes] requises pour jouer pleinement leur rôle dans la société ${ }^{2}$, l'évaluation a été conçue principalement en termes de compétences à mesurer. Cinq niveaux ont été définis pour les trois séries de compétences suivantes: retrouver de l'information, interpréter un texte, réfléchir sur le contenu. L'évaluation a porté sur trois domaines : culture scientifique, culture mathématique et compréhension de l'écrit.

2 La publication de l'enquête PISA $^{3}$ sous forme de palmarès international a provoqué réactions, commentaires et débats à l'intérieur des pays. Les répercussions n'ont pas eu toutes la même ampleur et ont porté, selon les résultats obtenus, sur une critique des structures éducatives (Allemagne), sur le bien-fondé des réformes (Québec), ou, pour la France, sur la remise en cause de certaines pratiques pédagogiques et sur le bon usage à faire des évaluations.

\section{Répercussions en Allemagne}

Classée en lecture entre la vingtième et la vingt-cinquième place, l'Allemagne se situe très largement au-dessous des moyennes scolaires des pays développés. Par-delà ce résultat brut, une analyse des évaluations montre un écart très important entre les meilleurs élèves et les plus faibles : alors que les meilleurs élèves allemands sont « à 
égalité » avec ceux d'autres pays, les plus faibles ont de moins bons résultats. L'école allemande est donc, pour ces jeunes moins performants, extrêmement contreproductive.

Les journaux allemands ont traduit les inquiétudes produites par les mauvais résultats de l'évaluation en demandant une réforme du système scolaire et en réclamant davantage de moyens ${ }^{4}$. Le monde patronal ${ }^{5}$ comme la classe politique ont fortement réagi. Une conférence des ministres de l'éducation des Länder ${ }^{6} \mathrm{~s}^{\prime} e s t$ tenue à la suite de la publication de l'enquête et le président de la République, Johannes Rau, est intervenu pour appeler à une réforme de l'éducation.

\section{Répercussions en France}

5 La France est dans la moyenne des pays, sauf en mathématiques (géométrie) où les résultats sont supérieurs. Les résultats sont inégaux selon les échelles de compétence évaluées et ont suscité des commentaires sur certaines pratiques pédagogiques. Ainsi, l'enquête a révélé une tendance propre aux élèves français qui préfèrent ne pas répondre plutôt que risquer une réponse erronée, à la différence, par exemple, des élèves américains.

6 Même si la presse française a longuement développé résultats et commentaires, les réactions ont été peu nombreuses dans le monde politique. En revanche, le milieu universitaire des sciences de l'éducation s'est interrogé sur la méthodologie mise en œuvre pour une évaluation internationale et sur l'utilisation qui pouvait être faite de ces résultats. Deux objections ont été émises : la première concerne la pertinence de comparaisons internationales, les systèmes éducatifs nationaux étant différents par leur histoire, leurs programmes et leurs missions; la seconde critique porte sur la réalisation de cette enquête confiée à un bureau d'experts très majoritairement anglosaxons $^{7}$ ce qui crée des biais culturels favorisant les élèves de culture anglo-saxonne ${ }^{8}$.

\section{Répercussions au Québec}

7 Les jeunes Québécois se sont classés au deuxième rang en mathématiques, au quatrième rang en sciences et compréhension écrite. Les milieux éducatifs ${ }^{9}$ du Québec voient dans ce bon résultat une justification des choix éducatifs et des réformes menées depuis vingt-cinq ans. Pour François Legault, ministre de l'Éducation à l'époque de la publication des résultats, il s'agit d'une confirmation et d'un encouragement aux récentes réformes conduites dans les cycles primaire et secondaire, et il déplore le peu de répercussions dans la presse des bons résultats obtenus ${ }^{10}$.

8 Les réactions de ces trois pays suscitent quelques remarques. Les comparaisons internationales, bien que difficiles à établir, jouent un rôle non négligeable dans l'aide à la décision politique. Une évaluation internationale confère, par un effet de mise à distance, une validité sur laquelle les pouvoirs publics peuvent s'appuyer, s'ils le souhaitent, pour modifier certaines caractéristiques de leur système éducatif qui seraient productrices d'inégalités et de mauvais résultats. L'OCDE a, dans ce domaine, pour objectif affiché d'aider les pays membres à établir les types d'enseignement et les organisations scolaires les plus efficaces et à promouvoir l'égalité des chances. 
Il existe certes des biais culturels qui limitent la portée des résultats et les rendent contestables, mais il n'en reste pas moins que cette enquête apporte des informations sur les structures, les pratiques et les attitudes des élèves.

Trois cycles d'évaluation sont prévus dans le cadre de PISA. En 2000, l'enquête a porté principalement sur la compréhension de l'écrit. En 2003, elle portera sur la culture mathématique et, en 2006, sur la culture scientifique. Il sera intéressant d'observer dans les prochaines années si la publication de ces résultats a été suivie d'effet comme le souhaite l'OCDE.

\section{NOTES}

1. Connaissances et compétences: des atouts pour la vie. Premiers résultats de Pisa 2000, 2001, OCDE (enseignement et compétences).

2. Extrait de la quatrième de couverture de l'ouvrage ci-dessus mentionné.

3. Les données sur lesquelles se fonde ce rapport ainsi qu'un certain nombre de rapports nationaux sont disponibles sur: www.pisa.oecd.org.

4. L'Allemagne dépense moins pour l'éducation que la moyenne des pays de l'OCDE.

5. Le président $\mathrm{du}$ syndicat patronal allemand BDA (Bundesvereinigung der Deutschen Arbeitgeberverbände) est intervenu en proposant plusieurs réformes éducatives.

6. L'éducation est de la compétence des Länder en Allemagne.

7. La réalisation du projet a été confiée à un consortium international d'organismes coordonné par l'Australian Council for Educational Research (ACER).

8. La publication d'un rapport technique sur les notions de comparabilité est annoncée par G. Lemaitre, l'un des responsables du programme PISA dans Nouveaux regards, $\mathrm{n}^{\circ} 16$, hiver 2001-2002).

9. Pour Jean Dionne, didacticien des mathématiques, mettre de plus en plus l'accent sur la créativité des jeunes a permis un accroissement des performances en français comme en sciences et mathématiques (Le Devoir, 12 janvier 2002).

10. Le Devoir, 10 mars 2002.

\section{INDEX}

Index géographique : Allemagne, France, Québec, Canada

Mots-clés : PISA : programme international pour le suivi des acquis des élèves 
AUTEUR

BERNADETTE PLUMELLE

Responsable du Centre de ressources documentaires du CIEP. [plumelle@ciep.fr] 